\title{
DESAFÍOS DE LAS NACIONES UNIDAS FRENTE AL COVID-19 ${ }^{1}$
}

\author{
CHALLENGES OF THE UNITED NATIONS FACING COVID-19
}

Por Angel V.Horna ${ }^{(*)}$

RESUMEN: El artículo examina algunos de los desafíos de la Organización de las Naciones Unidas tras el brote de la pandemia de la enfermedad por coronavirus de 2019 (COVID-19). Dichos desafíos van desde la renovación del multilateralismo hasta la posible reforma de la Organización, pasando por la necesidad de superar la inacción del Consejo de Seguridad, así como de garantizar el pleno respeto a los derechos humanos en tiempos de pandemia.

PALABRAS CLAVES: Naciones Unidas - COVID-19 - Derecho Internacional - Relaciones Internacionales - Organización Mundial de la Salud

ABSTRACT: The article examines some of the challenges of the United Nations following the outbreak of the coronavirus desease 2019 (COVID-19) pandemic. Those challenges range from the renewal of multilateralism to the possible reform of the Organization, and from the need to overcome the inaction of the Security Council to the necessity to ensure full respect of human rights in the times of the COVID-19 pandemic.

KEY WORDS: United Nations - COVID-19 - International Law - International Relations - World Health Organization

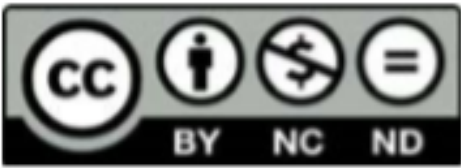

Artículo publicado bajo Licencia Creative Commons Atribución-No Comercial-Sin Derivar. (C) Universidad Católica de Córdoba

DOI http://dx.doi.org/10.22529/cdp.2020(8)04

\footnotetext{
${ }^{1}$ Artículo recibido el 10 de mayo de 2020 y aprobado para su publicación el 7 de junio de 2020.

Parte del contenido del artículo fue presentado en marco del Conversatorio Internacional "COVID 19 en América Latina: Situación y desafíos del Derecho Internacional", organizada por la Universidad San Ignacio de Loyola (Perú) el 11 de abril de 2020.

(*) Abogado, diplomático de carrera peruano, y profesor universitario. Doctor en Derecho Internacional por el Instituto de Altos Estudios Internacionales y del Desarrollo de Ginebra, Suiza (IHEID). Actualmente es Asesor de la Secretaría General de Relaciones Exteriores. Ejerció funciones en la Representación Permanente del Perú ante las Naciones Unidas con sede en Nueva York. Fue Vicepresidente de la Mesa del $72^{\circ}$ período de sesiones de la Sexta Comisión de la Asamblea General de Naciones Unidas. Previamente, integró la Asesoría para Asuntos de Derecho del Mar de la Cancillería peruana, habiendo participado en la preparación para la fase oral del Diferendo Marítimo Perú c. Chile ante la Corte Internacional de Justicia. Lo aquí expresado es de exclusiva responsabilidad del autor. angel.horna@graduateinstitute.ch
} 


\section{Introducción}

El presente artículo examina algunos de los desafíos que la Organización de las Naciones Unidas (ONU) enfrenta tras el brote de la pandemia de la enfermedad por coronavirus de 2019 (COVID-19). Dichos desafíos van desde la renovación del multilateralismo hasta la posible reforma de la Organización, pasando por la necesidad de superar la inacción del Consejo de Seguridad, así como de garantizar el pleno respeto a los derechos humanos en tiempos de pandemia. Los retos que se enumerarán son sin perjuicio del lugar central en la agenda de la ONU que en mi opinión continuarán ocupando la Agenda 2030 para el Desarrollo Sostenible y el Acuerdo de París.

El Secretario General de la ONU, António Guterres, ha calificado a la pandemia de la enfermedad por coronavirus de 2019 (COVID-19) como "la mayor prueba que el mundo ha enfrentado desde la formación de las Naciones Unidas, que tendrá profundas consecuencias sociales, económicas y políticas, incluyendo en relación a la paz y seguridad internacionales". ${ }^{2}$ En ese contexto, a continuación se discutirá lo que, a mi juicio, son siete desafíos de las Naciones Unidas frente al COVID-19, teniendo en cuenta los tres pilares de la Organización paz y seguridad, desarrollo y derechos humanos. ${ }^{3}$

\section{Renovar el multilateralismo}

Mucho se ha hablado del retroceso o declive del multilateralismo ${ }^{4}-$ y del derecho internacional- ${ }^{5}$, principalmente a propósito de la salida del Reino Unido de la Unión Europea

\footnotetext{
${ }^{2}$ Discurso del Secretario General de las Naciones Unidas, António Guterres, en sesión informativa del Consejo de Seguridad del 9 de abril de 2020; disponible en: https://www.un.org/press/en/2020/sgsm20041.doc.htm (recuperado el 18 de mayo de 2020).

3 Para una apreciación al respecto, ver e.g.: WEISS, Thomas G. y Sam DAWS, "World Politics: Continuity and Change since 1945", en: The Oxford Handbook on the United Nations, WEISS, Thomas G. y Sam DAWS (Eds.), Oxford: Oxford University Press, 2007, pp. 3-38; así como HANHIMÄKI, Jussi, The United Nations: A Very Short Introduction, Oxford: Oxford University Press, 2015, p. 135 y ss.

${ }^{4}$ Los conceptos de multilateralismo y derecho internacional, con cierta frecuencia, son asociados a la idea del "rules-based international order", que se puede encontrar - por ejemplo- en declaraciones de líderes del G20. En cuanto al multilateralismo, se trata del marco que emergió después de la segunda Guerra mundial y que rápidamente fue incluyendo al desarrollo económico, seguridad internacional, derechos humanos, salud global, y cuestiones ambientales. Se considera asimismo que el multilateralismo está expresado en múltiples organizaciones y foros, tales como las Naciones Unidas, el Fondo Monetario Internacional, la Organización Mundial del Comercio, la Organización del Tratado del Atlántico Norte, la Organización de Cooperación y Desarrollo Económico (OCDE), así como espacios más informales como el G7 o el G20. Ver asimismo: KISSINGER, Henry, "The Coronavirus Pandemic Will Forever Alter the World Order", en: The Wall Street Journal, 3 de abril de 2020; así como MORELAND, Will, "The purpose of multilateralism: A framework for democracies in a geopolitically competitive world", disponible en: https://www.brookings.edu/research/the-purpose-ofmultilateralism/ (recuperado el 18 de mayo de 2020).
} 
("Brexit") y la denominada vuelta al nacionalismo y el proteccionismo. En ese contexto, si bien la crisis es anterior a la pandemia de la enfermedad por coronavirus de 2019, es claro que ésta la exacerba.

A diferencia de lo que ocurrió, por ejemplo, con el auge del Estado Islámico de Iraq y el Levante (Dáesh), o el brote de la pandemia del Ébola, ambos en 2014, ${ }^{6}$ la comunidad internacional en su conjunto está hoy dividida y carece de liderazgo. Ello se manifiesta en una inadecuada reacción al COVID-19, al no haberse conseguido el consenso y coordinación necesarios entre Estados, para dar una respuesta basada en la unidad, la solidaridad y la cooperación multilateral.

Superar esta crisis del multilateralismo -ahora que es más necesario-, es pues el telón de fondo en el que la ONU debe actuar, y en consecuencia el primer gran desafío de la Organización. Es pertinente, sin embargo, destacar en este contexto esfuerzos como la denominada "Alianza para el Multilateralismo", que es una red informal de países -liderada por los Ministros de Asuntos Exteriores de Francia y Alemania - unidos en su convicción de que un orden multilateral basado en normas ("rules-based multilateral order") es la única garantía confiable para la estabilidad internacional y la paz; y que nuestros desafíos comunes sólo pueden ser resueltos a través de la cooperación. ${ }^{7}$ Dicha Alianza ha formulado además una propuesta relativa al suministro universal del eventual tratamiento y la vacuna e inmunización contra el COVID-19, con el fin de que sea tratado como bien público global (“global public good"). ${ }^{8}$

5 El retroceso del derecho internacional puede ser graficado en la política "America First" de la actual Administración de los EEUU, y en particular en el retiro de ese país de diversos tratados multilaterales, como por ejemplo el Acuerdo de París para el Cambio Climático, el Acuerdo Nuclear con Irán, y el Acuerdo Transpacífico de Cooperación Económica. Para mayor información, ver: $\mathrm{KOH}$, Harold, The Trump Administration and International Law, Oxford, Oxford University Press, 2019, 221 pp.

${ }^{6}$ Resolución 2178 (2014) del Consejo de Seguridad (sobre los Combatientes Terroristas Extranjeros), así como la labor y logros de la "Coalición Global contra Dáesh", disponible en: https://theglobalcoalition.org/en/ (recuperado el 18 de mayo de 2020). Asimismo, ver Resolución 2177 (2014) del Consejo de Seguridad (sobre el virus del Ébola).

7 Ver: https://multilateralism.org/ (recuperado el 18 de mayo de 2020). El presidente de Francia, Emmanuel Macron, considera a su turno que la pandemia es una oportunidad para el multilateralismo porque éste requiere una transformación de la globalización ("la crisis nos muestra que somos muy interdependientes"), añadiendo que probablemente surja también la idea de un "multilateralismo sanitario"; ver Entrevista a Emmanuel Macron en The Financial Times, 16 de abril de 2020, disponible en: https://www.ft.com/content/3ea8d790-7fd1-11ea-8fdb7ec06edeef84 (recuperado el 18 de mayo de 2020). Cfr. "Has covid-19 killed globalisation?", en The Economist, 14 de mayo de 2020, disponible en: https://www.economist.com/leaders/2020/05/14/has-covid-19-killedglobalisation (recuperado el 18 de mayo de 2020).

${ }^{8}$ Es de resaltar que el 16 de abril de 2020, dicha Alianza emitió un Comunicado Conjunto, que incluye como signatarios, entre otros, a los Cancilleres de Argentina, Chile, Colombia, Ecuador, México y el Perú, haciendo un llamamiento a la solidaridad global y la cooperación para luchar contra el COVID-19, disponible en: 


\section{Lograr una respuesta coordinada del sistema de las Naciones Unidas}

Ya desde 2004, el Grupo de alto nivel sobre las amenazas, los desafíos, y los cambios, establecido por el ex Secretario General Kofi Annan, recomendó reconstruir la salud pública global, con el fin de estar mejor preparados ante posibles casos de bioterrorismo o el brote de enfermedades infecciosas. ${ }^{9}$

Posteriormente, la Secretaría de la Organización Mundial de la Salud (OMS) alertó al mundo, antes del inicio de esta crisis. Por ejemplo, en febrero de 2018, en el marco de la Cumbre de Gobierno Mundial, realizada en Dubái, el Director General de la OMS, Tedros Adhanom Ghebreyesus, señaló que "una epidemia devastadora puede empezar en cualquier país, en cualquier momento, y matar millones de personas, porque no estamos preparados, porque somos vulnerables." 10 A pesar de ello, la respuesta del sistema de las Naciones Unidas ha sido dispersa.

En tal sentido, la OMS reaccionó conforme a su Constitución y su Reglamento Sanitario Internacional (RSI), revisado en 2005, ${ }^{11}$ determinando -el 30 de enero de 2020- la "emergencia de salud pública de importancia internacional"; y posteriormente -el 11 de marzo de 2020- la “pandemia". No obstante, lamentablemente -debido, entre otros, a los límites intrínsecos de esa agencia especializada- no se logró una adecuada preparación de la comunidad internacional.

https://www.auswaertiges-amt.de/en/newsroom/news/alliance-multilateralism-covid19/2333394 (recuperado el 18 de mayo de 2020).

${ }^{9}$ Informe del Grupo de Alto Nivel sobre las amenazas, los desafíos y el cambio, titulado: "Un mundo más seguro: la responsabilidad que compartimos", documento de Naciones Unidas A/59/565. Dicho informe, por ejemplo, en el para. 19, alertaba: "la seguridad del Estado más rico puede depender de la capacidad del Estado más pobre de contener una nueva enfermedad. Puesto que la duración de los vuelos internacionales es inferior al período de incubación de muchas enfermedades infecciosas, cualquiera de los 700 millones de pasajeros anuales que llevan esos vuelos puede ser, sin saberlo, un portador de enfermedad a escala mundial. El síndrome respiratorio agudo y grave (SARS) infectó a más de 8,000 personas en 30 países en un período de tres meses y provocó la muerte de casi 700 de ellas. Se estima que la pandemia de gripe de 1919 se cobró hasta 100 millones de víctimas, mucho más que la primera guerra mundial, en poco más de un año. Hoy en día un virus similar podría causar decenas de millones de muertes en mucho menos tiempo." Del mismo modo, acerca del régimen que gobierna las pandemias; ver por ejemplo: TELESETSKY, Anastasia, "International Governance of Global Health Pandemics", 23 de marzo de 2020, disponible en: https://www.asil.org/insights/volume/24/issue/3/international-governanceglobal-health-pandemics (recuperado el 18 de mayo de 2020).

10 Ver: Discurso del Director General de la OMS, Tedros Adhanom Ghebreyesus, en el World Government Summit, Dubai, 12 de febrero de 2019, disponible en: https://www.who.int/dg/speeches/detail/can-we-create-apandemic-free-world- (consultado el 11 de mayo de 2020).

${ }^{11}$ OMS, Constitución (1946), y Reglamento Sanitario Internacional (2005). 
Luego, con fecha 23 de marzo de 2020, el Secretario General hizo un Llamamiento al cese al fuego global. En él, señaló: “es hora de poner en cuarentena a los conflictos armados y centrarnos juntos en la verdadera lucha de nuestras vidas". ${ }^{12}$ Este llamamiento, por cierto, fue oportunamente complementado, el 9 de abril de 2020, con otro en el que el Secretario General instó a los Gobiernos a tener muy en cuenta los derechos de las mujeres y las niñas en sus esfuerzos contra el COVID-19. ${ }^{13}$

La Asamblea General de las Naciones Unidas, por su parte, adoptó la resolución 74/270, ${ }^{14}$ el 2 de abril de 2020. En ella la Asamblea "reafirma su adhesión a la cooperación internacional y al multilateralismo y su firme apoyo al papel central del sistema de las Naciones Unidas en la respuesta mundial a la pandemia de la enfermedad por COVID-19”. Seguidamente, la Asamblea General adoptó también la resolución 74/274, de fecha 20 de abril de 2020, en la que busca garantizar el acceso mundial a los medicamentos, las vacunas y el equipo médico con los que hacer frente a la COVID-19. ${ }^{15}$ Si bien es cierto estos logros son significativos, no parecen ser suficientes.

\section{Superar la parálisis del Consejo de Seguridad}

Como se sabe, la responsabilidad primordial del Consejo de Seguridad es el mantenimiento de la paz y seguridad internacionales, de conformidad con la Carta de las Naciones Unidas. El Consejo de Seguridad puede asimismo determinar la existencia de una amenaza a la paz o acto de agresión, hacer un llamado a las partes en una controversia a solucionarla por medios pacíficos y recomendar qué métodos o bajo qué términos llevar a cabo el arreglo. En algunos casos, el Consejo de Seguridad puede también imponer sanciones o inclusive autorizar el uso de la fuerza para mantener o restaurar la paz y seguridad internacionales.

Sin perjuicio de lo anterior, el Consejo de Seguridad también se ha ocupado en algunas ocasiones de asuntos vinculados a la salud pública. En el año 2000, con reticencias de China y Rusia, se discutió por primera vez las implicancias de la pandemia del VIH/Sida en el contexto de la paz y seguridad en África. Meses después se adoptó incluso una resolución que, en su

\footnotetext{
12 Ver: https://www.un.org/press/en/2020/sgsm20018.doc.htm.

13 Ver: https://www.un.org/press/en/2020/sgsm20040.doc.htm.

14 Resolución 74/270 de la Asamblea General de las Naciones Unidas.

15 Resolución 74/274 de la Asamblea General de las Naciones Unidas.
} 
parte preambular, destacaba que el VIH/Sida, "si no se controla, puede plantear un riesgo a la estabilidad y la seguridad". ${ }^{16}$

En ese escenario, fue recién mediante la resolución $2177(2014)^{17}$ que el Consejo de Seguridad determinó por primera vez que el alcance sin precedentes del brote del Ébola en África constituye una amenaza a la paz y seguridad internacionales. En otras palabras, declaró que una cuestión de salud pública podía ser un tema prioritario en la agenda del Consejo de Seguridad. Evidentemente, existen diferencias significativas entre el Ébola y el COVID-19. Por ejemplo, la letalidad de la primera, el alto índice de propagación de la segunda, el alcance del Ébola que se circunscribió al África Occidental, vis-à-vis el alcance cuasi global del COVID-19. Sin embargo, las similitudes entre ambos casos anunciaban la posibilidad que el Consejo de Seguridad logre un compromiso en las actuales negociaciones de una resolución. ${ }^{18}$

Parece ser que la actual parálisis se debe a la divergencia entre algunos de los miembros permanentes del Consejo (P5), a saber, China y Estados Unidos (EEUU), ${ }^{19}$ sobre el origen del virus (en particular, lenguaje relativo a la "necesidad de transparencia"), así como acerca de la posibilidad de referirse positivamente a la OMS (o incluso al lenguaje alternativo de "entidades de la ONU que luchan contra el COVID-19"). En tal sentido, EEUU bloqueó la propuesta franco-tunesina, que se venía discutiendo en Nueva York durante varias semanas. ${ }^{20}$

Dicha propuesta, entre otras cosas, buscaba endosar el Llamamiento al cese al fuego hecho por el Secretario General. Del mismo modo, ordenaba el reparto de información y ayuda

\footnotetext{
${ }^{16}$ Resolución 1308 (2000) del Consejo de Seguridad.

${ }^{17}$ Resolución 2177 (2014) del Consejo de Seguridad.

18 Se sabe que el 5 de mayo de 2020 los miembros del Consejo de Seguridad sostuvieron consultas oficiosas sobre el Proyecto de resolucion acerca del COVID-19. Posteriormente, trascendió en los medios de prensa internacionales que EEUU habría bloqueado la resolución el viernes 8 de mayo de 2020 debido a su negativa a incluir cualquier mención a la OMS (tal como habría propuesto China); ver e.g.: https://edition.cnn.com/2020/05/09/politics/us-rejects-un-coronavirus-resolution-china-who/index.html, y https://www.theguardian.com/world/2020/may/08/un-ceasefire-resolution-us-blocks-who (recuperados el 18 de mayo de 2020).

${ }^{19} \mathrm{La}$ rivalidad entre EEUU y China habría generado además algunas desavenencias entre los países europeos miembros del Consejo. Parece ser que frente a la propuesta franco-tunesina, Alemania y Estonia habrían planteado una alternativa; ver: y https://www.voanews.com/usa/europe-odds-us-china-fight-over-pandemic-un (recuperado el 18 de mayo de 2020). La tension entre EEUU y China incluye la denominada "Guerra de desinformación”, por la cual China habría buscado propagar teorías conspirativas mientras que EEUU respondió designando el virus como "el virus de Wuhan" o "el virus chino"; ver: Report by The Economist Intelligence Unit, 2020; disponible en: https://www.economist.com/leaders/2020/04/16/is-china-winning, (recuperado el 18 de mayo de 2020).

${ }^{20}$ GOWAN, Richard y Ashish PRADHAN, "Is All Hope lost for a Global Cease-Fire Resolution at the UN?, en: World Politics Review, disponible en sitio web de WPR (recuperado el 18 de mayo de 2020).
} 
humanitaria, pero sin afectar las operaciones de contraterrorismo de algunos de los miembros permanentes del Consejo; hacía una referencia positiva a las acciones que la OMS desarrolla frente a la pandemia; y disponía el levantamiento de algunos regímenes de sanciones. ${ }^{21}$

En cualquier caso, es necesario que el Consejo de Seguridad de las Naciones Unidas ponga de lado sus diferencias y logre unirse en torno a este tema, aun cuando ya han transcurrido varias semanas y parezca cada vez más lejano un resultado que sea relevante.

\section{Prevenir el impacto de la pandemia en la acción humanitaria}

El Covid-19 tiene un impacto sin precedentes en todos los países. Aquellos que ya tenían crisis humanitarias, o eran afectados por desastres naturales y/o cambio climático, son particularmente vulnerables, y están menos equipados. Ante ello el Secretario General anunció, a fines de marzo, un Plan Global para la Respuesta Humanitaria frente al COVID-19, presentado como una verdadera necesidad para la seguridad de la salud global. ${ }^{22}$

Cabe recordar que los principales conflictos contemporáneos incluyen a Siria, Yemen, Libia, la República Centroafricana, la República Democrática del Congo, Sudán, Sudán del Sur, Somalia, Myanmar, entre otros. Se trata pues de poblaciones vulnerables en zonas de conflicto que ya padecían penurias y que están viendo su situación empeorada.

Mención aparte merecen las propias Operaciones de Mantenimiento de la Paz (OMPs), que ya están viendo su accionar seriamente afectado. Se sabe, por ejemplo, que la rotación de tropas se ha suspendido hasta el 30 de junio. En tal sentido, las OMPs están evaluando qué funciones y actividades operativas son críticas y deben continuar, cuáles son importantes y deben ser adaptadas, y cuáles pueden suspenderse. ${ }^{23}$

${ }^{21}$ Ver: GAVER, Craig y Nishadee PERERA, "COVID-19 Symposium: Will the UN Security Council Act on COVID-19?”, en Opinio Juris, disponible en: http://opiniojuris.org/2020/04/04/covid-19-symposium-will-theun-security-council-act-on-covid-19/(recuperado el 18 de mayo de 2020).

22 OCHA, Global Humanitarian Response Plan Covid-19, Ginebra, Abril - Diciembre 2020.

23 "Protect, Help, Explain": UN Peackeeping responds to COVID-19, disponible en: https://medium.com/wethe-peoples/protect-help-explain-un-peacekeeping-responds-to-covid-19-d7ebe1a50ca5 (recuperado el 18 de mayo de 2020). 


\section{Garantizar el pleno respeto a los Derechos Humanos en tiempo de emergencia sanitaria global}

La Asamblea General, en su reciente resolución, ha reconocido también que "los más pobres y más vulnerables son los más afectados por la pandemia y que el impacto de la crisis destruirá los logros del desarrollo (...) y obstaculizará el progreso hacia el logro de los Objetivos del Desarrollo Sostenible (ODS)." ${ }^{24}$

En ese escenario, es imperativo que los Gobiernos garanticen el pleno respeto de los derechos humanos, ya que en la respuesta a la pandemia no hay cabida para ninguna forma de discriminación, incluyendo el racismo y la xenofobia. ${ }^{25}$

Vinculado a lo anterior, es también fundamental garantizar el respeto a los derechos humanos en el marco de los regímenes de excepción (Estados de Emergencia), y es que toda respuesta al nuevo coronavirus debe ser proporcionada, necesaria y no discriminatoria. Del mismo modo, dichas declaraciones de emergencia no deben ser usadas como base para atacar grupos particulares, minorías o individuos.

De otro lado, es pertinente reducir el riesgo de agitación social, así como estar alertas ante la tentación -de algunos gobiernos autoritarios- de explotar políticamente la crisis, incluso a través de la suspensión injustificada de procesos electorales.

Otro aspecto que considero se debe resaltar en este acápite es que los gobiernos se abstengan de bloquear el acceso a internet, dado que en una situación de emergencia el acceso a información es de vital importancia, en consecuencia no se pueden justificar restricciones al acceso a la información por motivos de orden público o seguridad nacional. Relacionado a lo anterior, resulta igualmente fundamental que los gobiernos y las empresas de internet aborden campañas malintencionadas de desinformación, proporcionando información fiable.

\footnotetext{
${ }^{24}$ Resolución 74/270 de la Asamblea General.

${ }^{25}$ Ver, inter alia: "Directrices esenciales para incorporar la perspectiva de derechos humanos en la atención de la pandemia por Covid-19", Oficina del Alto Comisionado de las Naciones Unidas para los Derechos Humanos, disponible en: https://acnudh.org/load/2020/04/V1.1 Directrices ONU-DH Covid19-y-Derechos-Humanos.pdf, (recuperado el 18 de mayo de 2020); "Respecting democracy, rule of law and human rights in the framework of the COVID-19 sanitary crisis - A toolkit for member states", Consejo de Europa, disponible en: https://rm.coe.int/sg-inf-2020-11-respecting-democracy-rule-of-law-and-human-rights-in-th/16809e1f40, (recuperado el 18 de mayo de 2020).
} 


\section{Cumplir un rol para la solución de controversias}

Más allá del rol de la Organización relativo a la mediación y los buenos oficios, existe también un posible papel de la Corte Internacional de Justicia, órgano judicial principal de la ONU. En efecto, en las últimas semanas se viene debatiendo, en particular en el ámbito académico, la posibilidad de llevar a un Estado -que no haya cumplido con la obligación de notificar oportunamente y compartir información temprana (tal como establecido en el RSI) sobre eventos en su territorio que puedan constituir una emergencia de salud pública de importancia internacional (Art. 6, RSI)- ante la Corte Internacional de Justicia. Por ejemplo, sobre la base del artículo 75 de la Constitución de la OMS, relativo a posibles controversias sobre la interpretación o aplicación de la Constitución que no sea resuelta mediante negociaciones o por la Asamblea Mundial de la Salud. ${ }^{26}$

Ello, si bien, plantea como primer obstáculo jurídico procesal la falta de jurisdicción, también podría acarrear posibles consecuencias políticas al Estado (o Estados) que decidieren aventurarse a tal empresa.

De otro lado, es pertinente recordar que, ya en los años noventa, la Organización Mundial de la Salud trató de solicitar una opinión consultiva de la Corte sobre los efectos en la salud de las armas nucleares, lo que fue rechazado por dicho órgano judicial. ${ }^{27}$ Posteriormente, una consulta similar fue formulada esta vez por la Asamblea General de Naciones Unidas y absuelta por la CIJ en 1996.

El segundo pedido de opinión consultiva versó acerca de si la amenaza o uso de armas nucleares es en cualquier circunstancia permitida bajo el derecho internacional. La Corte concluyó que "en vista del actual estado del derecho internacional y de los elementos factuales a su disposición, [ella] no puede concluir definitivamente si la amenaza o uso de armas nucleares serían lícitas o ilícitas en una circunstancia extrema de legítima defensa en la cual la misma supervivencia de un Estado esté en juego.”28

26 TZENG, Peter, "Taking China to the International Court of Justice over COVID-19", en: EJIL: Talk,
disponible en: https://www.ejiltalk.org/taking-china-to-the-international-court-of-justice-over-covid-19/
(recuperado el 18 de mayo de 2020 ).
27 Legality of the Use by a State of Nuclear Weapons in Armed Conflict, Advisory Opinion, ICJ Reports 1996, p. 66. Ver
también: BURCI, Gian Luca, "Health and Infectious Disease", en: WEISS, Thomas y Sam DAWS (eds.), Id., p.
589.
28 El texto original señaló: "in view of the current state of international law and of the elements of fact at its
disposal, [it] cannot conclude definitively whether the threat or use of nuclear weapons would be lawful or
CUADERNOS DE DERECHO PUBLICO 


\section{Considerar posibles iniciativas para la reforma de la ONU}

La comunidad internacional ha venido discutiendo, sin mayor éxito, la reforma de la ONU, así como la del Consejo de Seguridad, por más de veinticinco años. ${ }^{29}$ La pregunta $-\mathrm{y}$ uno de los grandes desafíos estructurales de la Organización- es si es que el mundo que emergerá después de esta crisis - que sin duda estará permanentemente alterado- podría generar las condiciones para un proceso de reforma diferente. Uno que tome en cuenta desarrollos que vamos observando hoy en día, como la aceleración de tendencias geopolíticas existentes, en particular la creciente rivalidad entre EEUU y China, así como el traslado del eje del poder económico de Occidente a Oriente..$^{30}$

En efecto, constatamos que esta crisis encontró a la comunidad internacional con determinados esfuerzos de liderazgo y otros vacíos de poder. Ello, a mi juicio, puede ofrecer una gran oportunidad de cambio.

El mundo que se asoma, no será uno en el que la principal amenaza sea el terrorismo internacional de Al-Qaida o el Estado Islámico, sino inter alia el cambio climático, la contaminación marina, las pandemias, el auge de determinadas nuevas tecnologías, y los autoritarismos nacionalistas.

unlawful in an extreme circumstance of self-defence, in which the very survival of a State would be at stake", en: Legality of the Threat or Use of Nuclear Weapons, Advisory Opinion, ICJ Reports 1996, p. 226.

29 Ver por ejemplo decisión 72/557, del 29 de junio de 2018, de la Asamblea General de las Naciones Unidas, acerca del proceso de negociaciones intergubernamentales sobre la reforma del Consejo de Seguridad (IGN). Proceso iniciado con la resolución 47/62 de la Asamblea General. Cuando se evoca la reforma del Consejo, con frecuencia, se hace referencia a tres hipótesis, a saber: i) la modificación de las disposiciones que rigen el "derecho de veto"; ii) la posibilidad de crear sea nuevos miembros permanentes, sea una nueva categoría de miembros; y iii) la necesidad de tornar más transparentes y eficaces los métodos de trabajo del Consejo; ver: DE LA SABLIERE, Jean-Marc, "La reforme de la composition du Conseil de sécurité", en: NOVOSSELOFF, Alexandra (Ed.), Le Conseil de sécurité des Nations Unies: entre impuissance et toute puissance, París: CNRS Editions, 2016, p. 261 y ss. Para mayor información sobre los procedimientos del Consejo de Seguridad, ver: SIEVERS, Loraine y Sam DAWS, The Procedure of the UN Security Council, Cuarta Edición, Oxford: Oxford University Press, 2014.

30 Ver: "Geopolitics after Covid-19: is the pandemic a turning point?" Report by The Economist Intelligence Unit, 2020 p. 1; disponible en: https://www.economist.com/leaders/2020/04/16/is-china-winning, (recuperado el 18 de mayo de 2020). 


\section{A manera de conclusión}

Considero que asistimos al inicio de un nuevo estadio en las relaciones internacionales, ${ }^{31}$ que empezó con esta pandemia, con efectos sin precedentes, y un impacto devastador en las sociedades y las formas de vida y subsistencia de las personas.

Sin embargo, considero igualmente que esta crisis -causada por la enfermedad del coronavirus (COVID-19)- puede mitigarse y resolverse con cooperación y solidaridad de las Naciones Unidas.

La ONU cumple en 2020 setenta y cinco años desde su fundación, y -tomando en cuenta su membresía global que le da legitimidad; su capacidad de convocatoria; y su experticia y presencia en el terreno- hay oportunidades para seguir fortaleciéndola. No olvidemos, finalmente, la célebre frase atribuida a un ex Embajador de EEUU ante la ONU, Henry Cabot Lodge Jr.,: "las Naciones Unidas no fueron creadas para llevarnos al cielo, sino para salvarnos del infierno". 32

${ }^{31}$ RHODES, Ben, “The 9/11 Era is Over", en: The Atlantic, 6 de abril de 2020, disponible en: https://amptheatlantic-

com.cdn.ampproject.org/c/s/amp.theatlantic.com/amp/article/609502/?fbclid=IwAR3QsuYZBSXAQfxfZsHz ntiXpMExIOxbixflNvTrlXvSallL1KZuBCpGuAQ (recuperado el 18 de mayo de 2020).

${ }^{32}$ Cfr.: LODGE, Henry Cabot, The storm has many eyes: a personal narrative, Norton, 1973, p. 155. Nótese que la frase es en ocasiones atribuida a Winston Churchill y figura también en el famoso discurso del ex Secretario General de Naciones Unidas, Dag Hammarskjöld, en la Universidad de California (Berkeley, California, 13 de mayo de 1954), donde dijo: "It has been said that the United Nations was not created in order to bring us to heaven, but in order to save us from hell". 